Fixed Point Theory, 19(2018), No. 1, 107-122

DOI 10.24193/fpt-ro.2018.1.09

http://www.math.ubbcluj.ro/ nodeacj/sfptcj.html

\title{
A STRONGLY CONVERGENT MODIFICATION OF THE PROXIMAL POINT ALGORITHM IN NONSMOOTH BANACH SPACES
}

\author{
SOUHAIL CHEBBI*, NAJLA ALTWAIJRY* AND HONG-KUN XU**,1 \\ *Department of Mathematics, College of Science, King Saud University \\ P.O. Box 2455, Riyadh 11451, Saudi Arabia \\ E-mails: schebbi@ksu.edu.sa, najla@ksu.edu.sa \\ ** Department of Mathematics, School of Science \\ Hangzhou Dianzi University, Hangzhou 310018, China \\ E-mail: xuhk@hdu.edu.cn
}

\begin{abstract}
Rockafellar's proximal point algorithm is known to be not strongly convergent in general in an infinite-dimensional Hilbert space. Effort has thus been made to modify this algorithm so that strong convergence is guaranteed. In this paper we provide a strongly convergent modification of Rockafellar's proximal point algorithm in a uniformly convex Banach space which is not necessarily smooth.
\end{abstract}

Key Words and Phrases: Maximal monotone operator, proximal point algorithm, strong convergence, generalized projection, uniformly convex Banach space, zero point.

2010 Mathematics Subject Classification: 90C25, 47H05, 90C30, 46B20, 47H09.

Acknowledgement. This project was funded by the National Plan for Science, Technology and Innovation (MAARIFAH), King Abdulaziz City for Science and Technology, Kingdom of Saudi Arabia, Award Number (12-MAT2658-02).

\section{REFERENCES}

[1] Y.I. Alber, S. Guerre-Delabriere, On the projection methods for fixed point problems, Analysis, 21(2001), 17-39.

[2] H.H. Bauschke, E. Matouskova, S. Reich, Projections and proximal point methods: convergence results and counterexamples, Nonlinear Anal., 56(2004), 715-738.

[3] H.H. Bauschke, J.V. Burke, F.R. Deutsch, H.S. Hundal, J.D. Vanderwerff, A new proximal point iteration that converges weakly but not in norm, Proc. Amer. Math. Soc., 133(6)(2005), 1829-1835.

[4] V. Barbu, Nonlinear Semigroups and Differential Equations in Banach Spaces, Noordhoff, 1976.

[5] V. Barbu, Th. Precupanu, Convexity and Optimization in Banach Spaces, Editura Academiei R.S.R., Bucharest, 1978.

[6] L.M. Bregman, Finding the common point of convex sets by the method of successive projection (Russian), Dokl. Akad. Nauk SSSR, 162(1965), 487-490.

\footnotetext{
${ }^{1}$ Corresponding author.
} 
[7] H. Brezis, Operateurs Maximaux Monotones et Semi-Groups de Contractions dans les Espaces de Hilbert, North-Holland, Amsterdam, 1973.

[8] R.E. Bruck, S. Reich, Nonexpansive projections and resolvents of accretive operators in Banach spaces, Houston J. Math., 3(1977), 459-470.

[9] R.S. Burachik, S. Scheimberg, A proximal point method for the variational inequality problem in Banach spaces, SIAM J. Control Optim., 39(2000), 1633-1649.

[10] J.V. Burke, M. Qian, A variable metric proximal point algorithm for monotone operators, SIAM J. Control Optim., 37(1998), 353-375.

[11] D. Butnariu, G. Kassay, A proximal-projection method for finding zeros of set-valued operators, SIAM J. Control Optim., 47(2008), 2096-2136.

[12] D. Butnariu, A.N. Iusem, On a proximal point method for convex optimization in Banach spaces, Numer. Funct. Anal. Optim., 18(1997), 723-744

[13] I. Cioranescu, Geometry of Banach Spaces, Duality Mappings and Nonlinear Problems, Kluwer Academic Publishers, 1990.

[14] F.H. Clarke, Optimization and Nonsmooth Analysis, John Wiley \& Sons, 1983.

[15] J. Eckstein, Nonlinear proximal point algorithms using Bregman functions, with application to convex programming, Math. Oper. Res., 18(1993), 202-226.

[16] J. Eckstein, D.P. Bertsekas, On the Douglas-Rachford splitting method and the proximal point algorithm for maximal monotone operators, Mathematical Programming, 55(1992), 293-318.

[17] E.G. Gol'shtein, N.V. Tret'yakov, Modified Lagrangians in convex programming and their generalizations, Mathematical Programming Study, 10(1979), 86-97.

[18] G. Gripenberg, On the asymptotic behaviour of nonlinear contraction semigroups, Math. Scand., 44(1979), 385-379.

[19] O. Güler, On the convergence of the proximal point algorithm for convex optimization, SIAM J. Control Optim., 29(1991), 403-419.

[20] H. Hundal, An alternating projection that does not converge in norm, Nonlinear Anal., 57(2004), 35-61.

[21] S. Kamimura, W. Takahashi, Strong convergence of a proximal-type algorithm in a Banach space, SIAM J. Optim., 13(2003), 938-945.

[22] A. Kaplan, R. Tichatschke, Proximal point approach and approximation of variational inequalities, SIAM J. Optim., 39(2000), 1136-1159.

[23] G. Marino, H.K. Xu, Convergence of generalized proximal point algorithms, Comm. Applied Anal., 3(2004), 791-808.

[24] B. Martinet, Regularisation d'inequations variationelles par approximations successives, Rev. Francaise Informat. Recherche Operationnelle (Ser. R-3), 4(1970), 154-158.

[25] C. Matinez-Yanes, H.K. Xu, Strong convergence of the CQ method for fixed point processes, Nonlinear Anal., 64(2006), 2400-2411.

[26] K. Nakajo, W. Takahashi, Strong convergence theorems for nonexpansive mappings and nonexpansive semigroups, J. Math. Anal. Appl., 279(2003), 372-379.

[27] O. Nevanlinna, S. Reich, Strong convergence of contraction semigroups and of iterative methods for accretive operators in Banach spaces, Israel J. Math., 32(1979), 44-58.

[28] S. Reich, An iterative procedure for constructing zeros of accretive sets in Banach spaces, Nonlinear Anal., 2(1978), 85-92.

[29] R.T. Rockafellar, Monotone operators and the proximal point algorithm, SIAM J. Control Optim., 14(1976), 877-898.

[30] R.T. Rockafellar, Augmented Lagrangians and applications of the proximal point algorithm in convex programming, Math. Oper. Res., 1(1976), 97-116.

[31] S. Burachik, S. Scheimberg, A proximal point method for the variational inequality problem in Banach spaces, SIAM J. Control Optim., 39(2001), 1633-1649.

[32] R.E. Showalter, Monotone Operators in Banach Spaces and Nonlinear Partial Differential Equations, Amer. Math. Soc., 1997.

[33] M.V. Solodov, B.F. Svaiter, Forcing strong convergence of proximal point iterations in a Hilbert space, Mathematical Programming, Ser. A, 87(2000), 189-202.

[34] H.K. Xu, Inequalities in Banach spaces with applications, Nonlinear Anal., 16(1991), 1127-1138. 
[35] H.K. Xu, Iterative algorithms for nonlinear operators, J. London Math. Soc., 66(2002), 240-256.

[36] H.K. Xu, Asymptotic behavior of a gradient flow, Comm. Appl. Nonlinear Anal., 7(2004), 11-17.

Received: April 14, 2016; Accepted: May 25, 2016. 